\title{
TRATAMENTO TERCIÁRIO DE ESGOTO SANITÁRIO VISANDO O REÚSO DA ÁGUA
}

\author{
L. A. OLIVEIRA ${ }^{1}$ e V. S. MADEIRA ${ }^{2}$ \\ ${ }^{1}$ Universidade Federal da Paraíba \\ ${ }^{2}$ Universidade Federal da Paraíba, Departamento de Engenharia Química \\ E-mail para contato: luanadeoliveira_@hotmail.com
}

\begin{abstract}
RESUMO - O esgoto sanitário é um efluente formado por despejos de diversas origens como, doméstico, comercial, área institucional e industrial. Nesse trabalho o efluente utilizado é o esgoto doméstico previamente tratado por processos físicos e bioquímicos de lagoas de estabilização. Este efluente foi tratado por coagulação, utilizando o sulfato férrico, o cloreto férrico e o sulfato de alumínio como agentes coagulantes, seguida da floculação, decantação e filtração. O objetivo do trabalho é produzir água tratada que possa ser reutilizada para fins como, irrigação de jardins e campos agrícolas, lavagem de pisos, pastagens, etc. Foi realizado um planejamento experimental onde o $\mathrm{pH}$ e a dosagem são as variáveis de entrada do programa computacional Statistica 7. A partir das superfícies de respostas foi possível encontrar o ponto ótimo de cada coagulante, onde os melhores valores da dosagem foram de 60 $\mathrm{mg} / \mathrm{L}$ para o sulfato férrico e cloreto férrico e de $40 \mathrm{mg} / \mathrm{L}$ para o sulfato de alumínio, e o melhor $\mathrm{pH}$ foi igual a 5 para todos os coagulantes. As melhores eficiências de remoção dos poluentes foram obtidas para o sulfato férrico, seguido do sulfato de alumínio e por último o cloreto férrico. Sendo obtidas remoções de $95 \%$ na cor, $94 \%$ na turbidez e $79 \%$ na DQO, utilizando o sulfato de alumínio. Foi possível ainda determinar a resistência específica da torta, obtendo valores de $2,52 \times 10^{16} \mathrm{~m} / \mathrm{kg}$ para sulfato férrico, $1,91 \times 10^{16} \mathrm{~m} / \mathrm{kg}$ para sulfato de alumínio e $1,18 \times 10^{16} \mathrm{~m} / \mathrm{kg}$ para o cloreto férrico.
\end{abstract}

\section{INTRODUÇÃO}

Com a crescente preocupação com o meio ambiente, o tratamento de efluentes vem cada vez mais sendo estudado e otimizado a fim de encontrar melhorias em seu processo para que o impacto ambiental seja reduzido. O esgoto sanitário é um efluente formado por despejos de diversas origens como, esgoto doméstico, esgoto comercial, esgoto da área institucional e esgoto industrial. Este trabalho tem por objetivo aplicar um tratamento terciário ao esgoto doméstico previamente tratado, produzido pela empresa Companhia de Águas e Esgotos da Paraíba (CAGEPA), visando produzir água de reúso para fins que exijam qualidade de água não potável, 


\section{9 a 22 de outubro de 2014 \\ Florianópolis/SC}

mas sanitariamente segura, tais como, a irrigação de jardins, a lavagem de pisos e dos veículos automotivos, na descarga dos vasos sanitários, na irrigação dos campos agrícolas, pastagens e etc. (NBR 13969/97). O efluente utilizado é previamente tratado por processos físicos, de gradeamento e caixa de areia, e por processos bioquímicos, por lagoas de estabilização (facultativa e anaeróbia) e o tratamento terciário realizado é de coagulação, floculação, decantação e filtração. A motivação para o desenvolvimento deste trabalho está em produzir água de reúso, especialmente na região Nordeste do país, visando favorecer as áreas escassas de água e contribuir para a agricultura familiar. Pretende-se, com o tratamento, o atendimento da NBR 13.969, Classe 1, que implica na obtenção de uma água tratada com turbidez menor do que 5 FTU, coliformes fecais menores do que 200 NMP/100mL e pH entre 6 e 8.

A estratégia do reúso de água é utilizada em várias cidades do mundo, como a cidade de Calcutá na Índia que desde 1929 praticamente todo o esgoto bruto da cidade é utilizado em tanques de criação de peixes e a cidade de São Petersburgo na Flórida que utiliza água de reúso desde 1977 para a irrigação de parques, campos de golfe, pátios escolares, gramados residenciais e reposição em torres de resfriamento (PROSAB, 2006; Mancuso e Santos, 2003).

\section{METODOLOGIA}

Os experimentos de coagulação, floculação e decantação foram realizados para selecionar o ponto ótimo de cada coagulante, ou seja, a melhor combinação de pH e dosagem dos coagulantes (sulfato férrico, cloreto férrico e sulfato de alumínio) que terão a maior eficiência de remoção dos poluentes. As dosagens testadas foram de 20, 40 e $60 \mathrm{mg} / \mathrm{L}$ para os coagulantes férricos e 20, 30 e $40 \mathrm{mg} / \mathrm{L}$ para o sulfato de alumínio, e foram testados os pHs 5, 6 e 7. Foi realizado um planejamento experimental fatorial $2^{2}$ com duas repetições no ponto central, resultando em seis experimentos para cada coagulante. O programa computacional Statistica 7 foi utilizado e através das superfícies de respostas pôde-se selecionar o ponto ótimo, ou seja, o que obteve as melhores porcentagens de remoção dos poluentes.

Os experimentos foram baseados em Richter (2009), onde, inicialmente era adicionado um litro do efluente em cada jarro do aparelho jar test, da marca Alfakit, e era iniciada a rotação de $180 \mathrm{rpm}$. As doses de coagulante eram adicionadas e ajustava-se o pH com adição de hidróxido de sódio $(1 \mathrm{~N})$ ou de ácido sulfúrico $(2 \mathrm{~N})$. Após ajuste de $\mathrm{pH}$, deixava-se em agitação máxima por um minuto e em seguida reduzia a rotação do aparelho para $50 \mathrm{rpm}$ e esperava-se a floculação por 15 minutos, posteriormente, desliga-se o aparelho e deixa decantar por uma hora. Após decantação, uma amostra do sobrenadante era retirada para realizar as análises de cor verdadeira (mgPt/L), turbidez (UNT ou FTU), cor predominante $(\mathrm{mgPt} / \mathrm{L})$, sólidos suspensos totais (SST $\mathrm{mg} / \mathrm{L}$ ), demanda química de oxigênio (DQO $-\mathrm{mg} / \mathrm{L}$ ), demanda biológica de oxigênio (DBO $\mathrm{mg} / \mathrm{L})$, carbono orgânico total (COT $-\mathrm{mg} / \mathrm{L})$, nitrato $\left(\mathrm{NO}_{3}-\mathrm{mg} / \mathrm{L}\right)$ e surfactantes $(\mathrm{SUR}-\mathrm{mg} / \mathrm{L})$. Os procedimentos de análises foram baseados em CLESCERI et al. (1999) e as análises de cor, turbidez e cor predominante foram realizadas com o uso de espectrofotômetro, modelo U2M da 
marca Quimis, e as análises de SST, DQO, DBO, COT, $\mathrm{NO}_{3}$ e SUR foram realizadas no equipamento Pastel UV, da marca Secomam. Com os resultados e as análises das superfícies de resposta, pôde-se encontrar o ponto ótimo de cada coagulante.

Após selecionado o ponto ótimo, foi realizado o tratamento terciário completo (coagulação/floculação/decantação/filtração), onde a filtração do sobrenadante foi realizada através de um sistema de filtração ligado a uma bomba de vácuo da marca Solab, modelo SL 60. A filtração do lodo decantado também foi realizada com o objetivo de encontrar a resistência específica da torta, a fim de utilizar estes dados no dimensionamento de um filtro industrial. Para isso, um volume conhecido de lodo era filtrado e computava-se o tempo que esse lodo passava para ser filtrado, com esses dados foi possível obter a curva de filtração ( $\mathrm{t} / \mathrm{V}$ versus $\mathrm{V}$ ) e com a equação da reta foi possível encontrar o valor de $\mathrm{Kp}$, parâmetro necessário para encontrar a resistência específica da torta $(\alpha)$, como pode ser observado pelas equações retiradas do Foust et al. (1982).

$$
\begin{aligned}
& \frac{d t}{d V}=\underbrace{\frac{\mu \times \alpha \times C_{s, a}}{A^{2} \times(-\Delta p)}}_{\mathrm{K}_{\mathrm{p}}} V+\underbrace{\frac{\mu}{A \times(-\Delta p)} R_{m}}_{\mathrm{B}} \\
& \frac{d t}{d V}=K_{p} V+B
\end{aligned}
$$

Integrando obtêm-se a Equação 3:

$$
\frac{t}{V}=\frac{K_{p}}{2} V+B
$$

A partir do valor de Kp pode-se encontrar a resistividade da torta $(\alpha)$, pela Equação 4:

$$
\alpha=\frac{K_{p} \times A^{2} \times(-\Delta p)}{\mu \times C_{s, a}}
$$

Onde: $\alpha$ é a resistência específica da torta $(\mathrm{m} / \mathrm{kg}) ; \mathrm{K}_{\mathrm{p}}$ é obtido pelo coeficiente angular da reta $\left(\mathrm{s} / \mathrm{m}^{6}\right)$; A é a área transversal do filtro $\left(\mathrm{m}^{2}\right) ;\left(-\Delta_{\mathrm{p}}\right)$ é a pressão que está ocorrendo a filtração $(\mathrm{Pa}) ; \mu$ é a viscosidade dinâmica do fluido (Pa.s); $\mathrm{C}_{\mathrm{s}, \mathrm{a}}$ é a concentração de sólidos na alimentação $\left(\mathrm{kg}_{\text {sólidos }} / \mathrm{m}^{3}\right.$ filtrado $) ; \mathrm{V}$ é o volume total acumulado de filtrado $\left(\mathrm{m}^{3}\right)$; $\mathrm{t}$ é o tempo (s).

Para encontrar Cs, a foi utilizada uma termobalança da marca BEL, onde colocava-se um volume conhecido do lodo e iniciava-se a secagem (com um máximo de $110^{\circ} \mathrm{C}$ ) com objetivo de retirar toda a água presente na amostra ficando apenas o sólido. Com a massa de sólidos e o volume que foi adicionado na termobalança é possível calcular o Cs,a. A filtração à vácuo foi realizada com uma diferença de pressão de $600 \mathrm{mmHg}$, ou seja, 79.993,42 $\mathrm{Pa}$, com área de filtração de $0,00126 \mathrm{~m}^{2}$ e viscosidade dinâmica do efluente igual a $0,0008903 \mathrm{~Pa} . \mathrm{s}\left(25^{\circ} \mathrm{C}\right)$. 


\section{RESULTADOS E DISCUSSÃO}

Após os experimentos de coagulação, floculação e decantação, amostras do sobrenadante foram retiradas para análise das respostas dos poluentes. Através das superfícies de resposta pôde-se escolher o ponto ótimo para cada coagulante. A Tabela 1 mostra as respostas da matriz de planejamento e a Figura 1 mostra as superfícies de resposta para os poluentes cor, turbidez e DQO para o tratamento com o sulfato férrico.

Tabela 1 - Respostas do planejamento fatorial para o sulfato férrico

Exp. pH Dosagem Cor Turbidez Cor pred. SST DQO DBO COT NO $\mathrm{NUR}_{3}$

\begin{tabular}{cccccccccccc}
\hline 1 & $-(5)$ & $-(20)$ & 205,273 & 25,3470 & 142,9055 & 5 & 128 & 18 & 26 & 1 & 1,9 \\
\hline 2 & $+(7)$ & $-(20)$ & 419,663 & 49,9238 & 439,1535 & 82 & 210 & 29 & 43 & 1 & 1,8 \\
\hline $\mathbf{3}$ & $-\mathbf{( 5 )}$ & $\mathbf{+ ( 6 0 )}$ & $\mathbf{4 5 , 4 5 5}$ & $\mathbf{6 , 1 3 2 5}$ & $\mathbf{2 5 , 9 6 5 5}$ & $\mathbf{1 0}$ & $\mathbf{3 6}$ & $\mathbf{1 5}$ & $\mathbf{1 1}$ & $\mathbf{1}$ & $\mathbf{2 , 5}$ \\
\hline 4 & $+(7)$ & $+(60)$ & 64,945 & 8,8136 & 41,5575 & 40 & 115 & 16 & 23 & 1 & 1,9 \\
\hline 5 & $0(6)$ & $0(40)$ & 53,251 & 7,47305 & 37,6595 & 16 & 49 & 18 & 15 & 1 & 2,7 \\
\hline 6 & $0(6)$ & $0(40)$ & 57,149 & 6,57935 & 29,8635 & 24 & 63 & 18 & 18 & 1 & 2,3
\end{tabular}

Onde: Dosagem (mg/L); Cor (mg/L PtCo); Turbidez (FTU); Cor pred. (mg/L PtCo); SST, DQO, DBO, COT, $\mathrm{NO}_{3}$ e SUR em $(\mathrm{mg} / \mathrm{L})$.
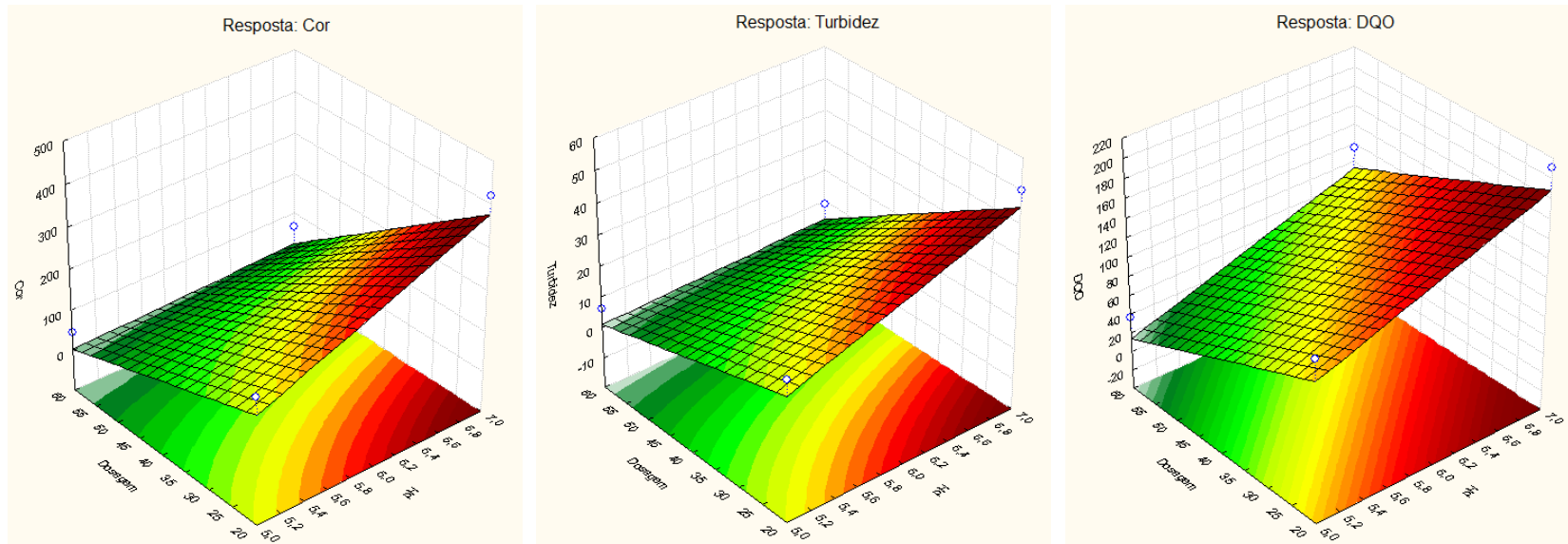

Figura 1 - Superfícies das respostas cor, turbidez e DQO para o sulfato férrico. 
A Tabela 2 mostra as respostas da matriz de planejamento e a Figura 2 mostra as superfícies de resposta para os poluentes cor, turbidez e DQO para o tratamento com o cloreto férrico.

Tabela 2 - Respostas do planejamento fatorial para o cloreto férrico

\section{Exp. pH Dosagem Cor Turbidez Cor pred. SST DQO DBO COT NO $\mathrm{NUR}_{3}$}

\begin{tabular}{cccccccccccc}
\hline 1 & $-(5)$ & $-(20)$ & 361,194 & 35,625 & 252,050 & 35 & 95 & 30 & 27 & 1 & 3,1 \\
\hline 2 & $+(7)$ & $-(20)$ & 649,646 & 74,947 & 692,524 & 52 & 143 & 41 & 38 & 1 & 2,1 \\
\hline $\mathbf{3}$ & $-\mathbf{( 5 )}$ & $\mathbf{+ ( 6 0 )}$ & $\mathbf{1 0 3 , 9 2 6}$ & $\mathbf{1 3 , 7 2 9}$ & $\mathbf{8 4 , 4 3 6}$ & $\mathbf{8}$ & $\mathbf{3 5}$ & $\mathbf{1 8}$ & $\mathbf{1 2}$ & $\mathbf{1}$ & $\mathbf{3 , 1}$ \\
\hline 4 & $+(7)$ & $+(60)$ & 407,970 & 38,753 & 337,806 & 22 & 68 & 28 & 22 & 1 & 2,7 \\
\hline 5 & $0(6)$ & $0(40)$ & 427,460 & 43,668 & 392,378 & 29 & 84 & 33 & 27 & 1 & 3,4 \\
\hline 6 & $0(6)$ & $0(40)$ & 411,868 & 45,455 & 411,868 & 30 & 89 & 30 & 26 & 1 & 3,0
\end{tabular}

Onde: Dosagem (mg/L); Cor (mg/L PtCo); Turbidez (FTU); Cor pred. (mg/L PtCo); SST, DQO, DBO, COT, $\mathrm{NO}_{3}$ e SUR em (mg/L).
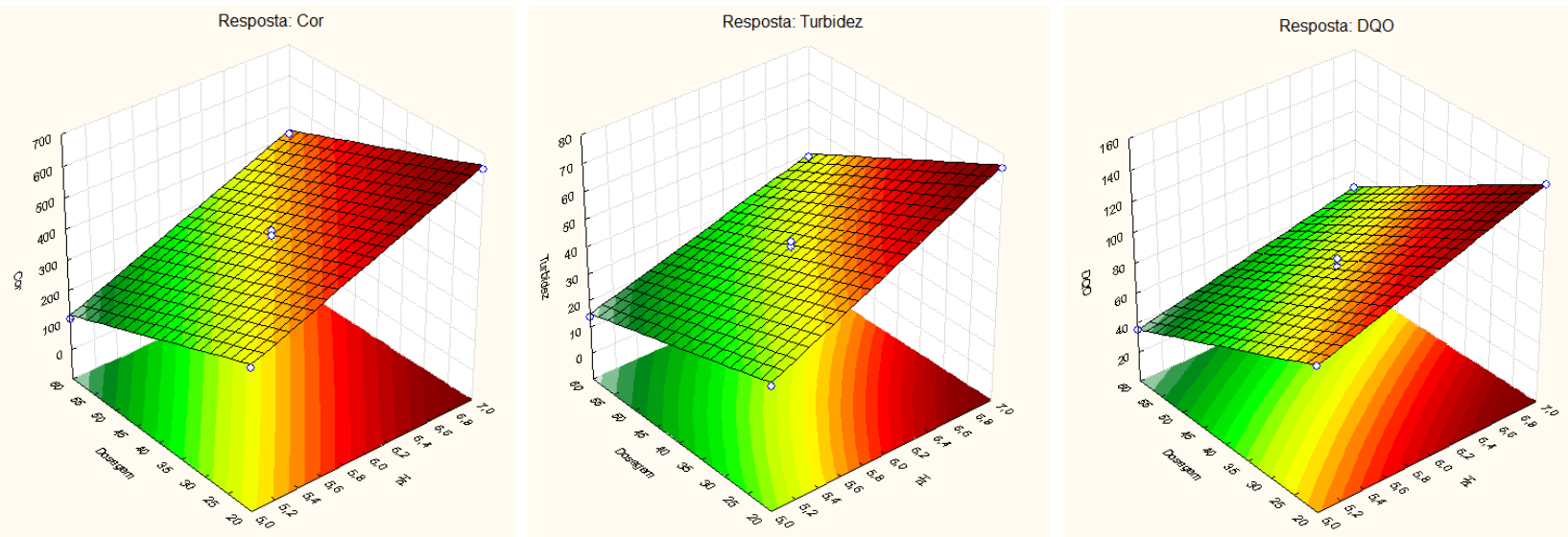

Figura 2 - Superfícies das respostas cor, turbidez e DQO para o cloreto férrico.

A Tabela 3 mostra as respostas da matriz de planejamento e a Figura 3 mostra as superfícies de resposta para os poluentes cor, turbidez e DQO para o tratamento com o sulfato de alumínio. 
Tabela 3 - Respostas do planejamento fatorial para o sulfato de alumínio

\section{Exp. pH Dosagem Cor Turbidez Cor pred. SST DQO DBO COT $\mathrm{NO}_{3}$ SUR}

\begin{tabular}{cccccccccccc}
\hline 1 & $-(5)$ & $-(20)$ & 170,192 & 20,879 & 131,212 & 12 & 45 & 21 & 16 & 1 & 3,1 \\
\hline 2 & $+(7)$ & $-(20)$ & 209,172 & 20,432 & 135,110 & 11 & 50 & 25 & 17 & 1 & 3,2 \\
\hline $\mathbf{3}$ & $-\mathbf{( 5 )}$ & $\mathbf{+ ( 4 0 )}$ & $\mathbf{8 0 , 5 3 8}$ & $\mathbf{1 1 , 0 4 8}$ & $\mathbf{6 8 , 8 4 4}$ & $\mathbf{6}$ & $\mathbf{3 3}$ & $\mathbf{1 8}$ & $\mathbf{1 2}$ & $\mathbf{1}$ & $\mathbf{2 , 8}$ \\
\hline 4 & $+(7)$ & $+(40)$ & 107,824 & 13,729 & 76,640 & 6 & 43 & 22 & 15 & 1 & 3,4 \\
\hline 5 & $0(6)$ & $0(30)$ & 84,436 & 12,388 & 72,742 & 5 & 34 & 19 & 13 & 1 & 3,3 \\
\hline 6 & $0(6)$ & $0(30)$ & 115,620 & 12,388 & 72,742 & 5 & 35 & 20 & 13 & 1 & 3,4
\end{tabular}

Onde: Dosagem (mg/L); Cor (mg/L PtCo); Turbidez (FTU); Cor pred. (mg/L PtCo); SST, DQO, DBO, COT, $\mathrm{NO}_{3}$ e SUR em (mg/L).
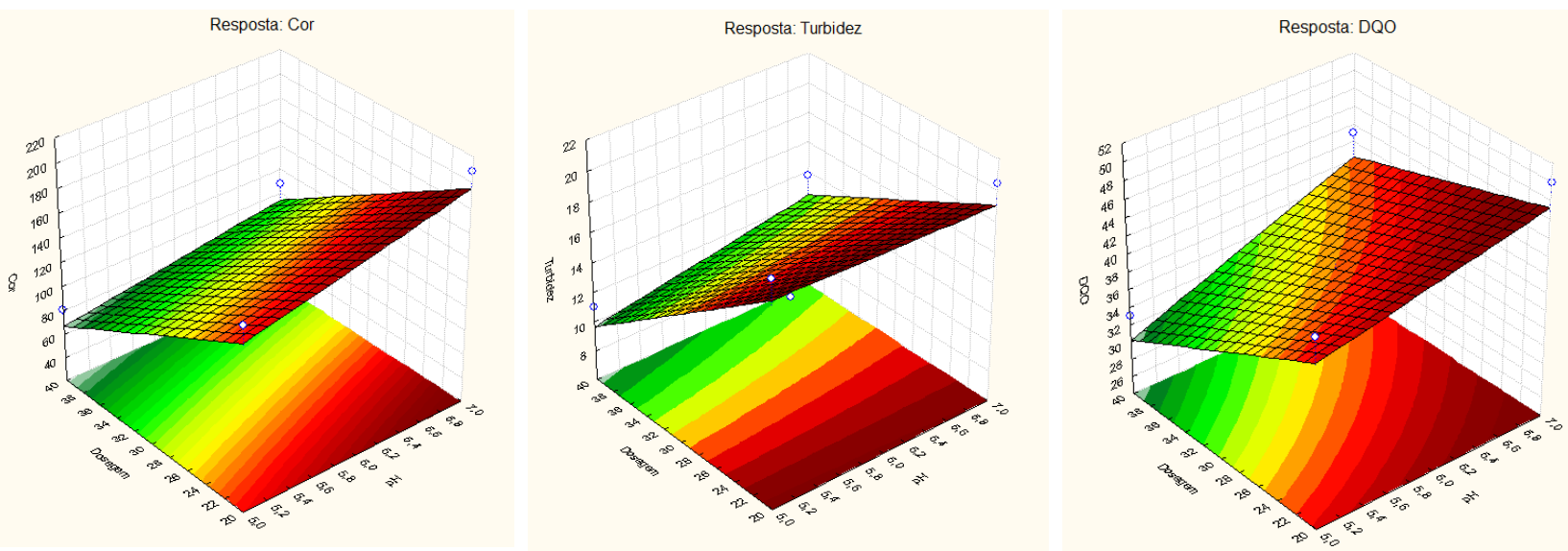

Figura 3 - Superfícies das respostas cor, turbidez e DQO para o sulfato de alumínio.

Pelas Tabelas e Figuras de 1 a 3 observou-se que os menores valores para as respostas foram obtidas para o ponto 3 , ou seja, o ponto ótimo escolhido foi $\mathrm{pH}$ igual a 5 e dosagem igual a $60 \mathrm{mgFe} e^{+3} / \mathrm{L}$ para os coagulantes férricos e $\mathrm{pH}$ igual a 5 e dosagem igual a $40 \mathrm{mgAl}^{+3} / \mathrm{L}$ para o sulfato de alumínio.

Selecionado o ponto ótimo de cada coagulante, foi realizado o tratamento completo (coagulação/floculação/decantação/filtração) do efluente objetivando o reúso da água. A Figura 4 mostra as porcentagens de remoção dos poluentes para os três agentes coagulantes. 


\section{Remoção dos poluentes no tratamento terciário do efluente}

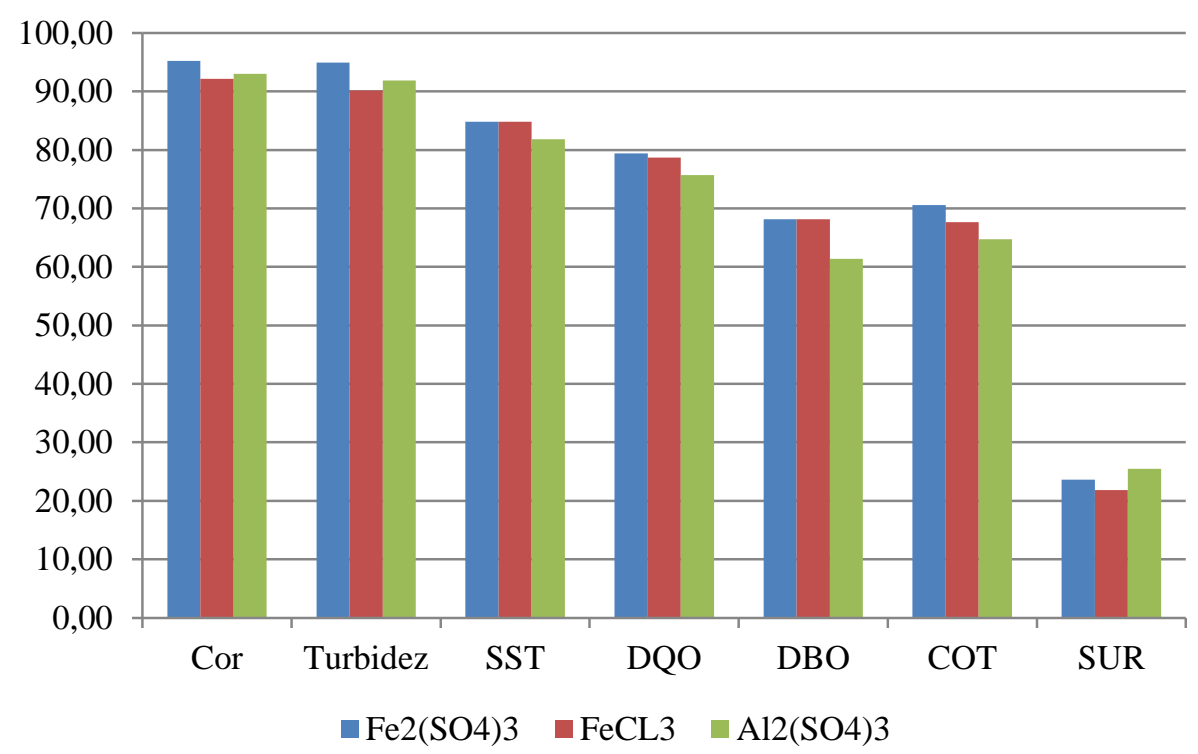

Figura 4 - Comparação da porcentagem de remoção dos poluentes no tratamento terciário utilizando três diferentes coagulantes.

Observa-se que o sulfato férrico obteve a melhor eficiência dentre os três coagulantes analisados, seguido do sulfato de alumínio e por último o cloreto férrico, indicando que o ânion sulfato tem melhor comportamento para o tratamento de efluentes do que o ânion cloreto, mesmo sendo utilizada uma menor concentração no tratamento com o sulfato de alumínio $\left(40 \mathrm{mgAl}^{+3} / \mathrm{L}\right)$ do que com o cloreto férrico $\left(60 \mathrm{mgFe}^{+3} / \mathrm{L}\right)$. Isso acontece porque os flocos formados utilizando os coagulantes de sulfato são maiores que os de cloreto, portanto há uma maior eficiência na remoção. Ou seja, os coagulantes de sulfato férrico e de alumínio, tem grande potencial nos tratamentos de efluentes.

Para a filtração do lodo decantado, foi possível obter as resistências específicas da torta para os três coagulantes analisados. Sendo a resistência da torta do sulfato férrico a maior $\left(2,52 \times 10^{16} \mathrm{~m} / \mathrm{kg}\right)$ dentre os três coagulantes, seguido da resistência do sulfato de alumínio $\left(1,91 \times 10^{16} \mathrm{~m} / \mathrm{kg}\right)$ e do cloreto férrico $\left(1,18 \times 10^{16} \mathrm{~m} / \mathrm{kg}\right)$. Esse foi um resultado desfavorável, pois, observando a Equação 1 tem-se que, uma maior resistência, implica em maior tempo de filtração, o que não é bom para um processo industrial. 


\section{CONCLUSÃO}

O tratamento do esgoto doméstico por coagulação/floculação/decantação/filtração se mostrou bastante eficaz na remoção dos poluentes, obtendo remoções de $95 \%$ para a cor, $94 \%$ para turbidez e $79 \%$ para DQO quando tratado com o sulfato férrico. Embora o parâmetro turbidez tenha ficado fora do aceitável pela NBR 13.969/97, uma simples cloração poderia ser suficiente para tornar apta a água tratada. O coagulante sulfato de alumínio obteve melhor eficiência, seguido do sulfato de alumínio e por último o cloreto férrico, indicando que o ânion sulfato tem melhor comportamento para o tratamento de efluentes do que o ânion cloreto, sendo explicado pelo fato de flocos de sulfato serem maiores que os de cloreto.

Por fim, os valores das resistências específicas da torta foram bastante próximos, sendo de $2,52 \times 10^{16} \mathrm{~m} / \mathrm{kg}$ para o sulfato férrico, $1,91 \times 10^{16} \mathrm{~m} / \mathrm{kg}$ para o sulfato de alumínio e $1,18 \times 10^{16}$ $\mathrm{m} / \mathrm{kg}$ para o cloreto férrico. Com esse parâmetro é possível dimensionar o tempo de filtração para um processo industrial.

\section{REFERÊNCIAS}

CLESCERI, L. S.; GREENBERG, A. E.; EATON, A. D. Standard Methods for the Examination of Water and Wasterwater. American Public Health Association (APHA), $20^{a}$ edição, 1999.

FOUST, A. S.; WENZEL, L. A.; CLUMP, C. W.; MAUS, L.; ANDERSEN, L. B. Princípios das operações unitárias. Editora LTC, 1982.

MANCUSO, P.C. S.; SANTOS, H. F. Reúso de água. Editora Manole, 2003.

NBR 13969/97. Tanques sépticos - Unidades de tratamento complementar e disposição final dos efluentes líquidos - Projeto, construção e operação. Associação Brasileira de Normas Técnicas ABNT, 1997.

PROSAB. Programa de Pesquisa em Saneamento Básico. Ministério da Ciência e Tecnologia. FINEP, 2006.

RICHTER, C. A. Água: métodos e tecnologia de tratamento. São Paulo: Editora Blucher, p. 307$311,2009$. 